Check for updates

The BMJ

Cite this as: BMJ2020;371:m4099 http://dx.doi.org/10.1136/bmj.m4099 Published: 22 October 2020

\title{
Covid-19: Increased risk among ethnic minorities is largely due to poverty and social disparities, review finds
}

\section{Gareth lacobucci}

Most of the increased risk of infection and death from covid-19 among people from ethnic minorities is explained by factors such as occupation, where people live, their household composition, and pre-existing health conditions, a government review has concluded.

But the first quarterly report from the government's Race Disparity Unit (RDU), based in the Cabinet Office, notes that a part of the excess risk "remains unexplained" in some groups such as black men, and it said that further work was needed to understand which factors may be causing the disparities.

The report summarises progress towards tackling covid-19 health inequalities since Public Health England published a review on 2 June setting out the disparities in risks and outcomes. ${ }^{2}$ Since then the RDU has been working with the equalities minister, Kemi Badenoch, across government, with the Office for National Statistics, and with academics to examine what is driving these disparities and how to tackle them.

Raghib Ali, one of the government's new expert advisers on covid and ethnicity, said there was "good evidence" that most excess risk among ethnic minorities was explained by risk factors other than ethnicity.

He told a Science Media Centre briefing on 21 October, “It's not that [ethnic minority people] won't be at increased risk-we will still have those risk factors, but we have to address the risk factors rather than just saying it's ethnicity.

“We didn't have all this information at the beginning, so it was reasonable to use ethnicity as a proxy early on. But now we need to extend it to the whole population. It's not very resource intensive to roll out a personal risk calculator to everybody. We should be able to target interventions at everyone who is at high risk."

Ali added that he saw no evidence that structural racism had contributed to the higher risk of infection and death in ethnic minorities, as Public Health England had suggested in its June report.

He said, "The second Public Health England report said that racism may contribute to some of these disparities. But they didn't present any objective evidence for that-it was based really on the views of 4000 stakeholders.

"There is certainly no evidence from either the ONS [Office for National Statistics] paper or the OpenSafely data that blacks and south Asians were treated any differently once they reached hospital. I don't think structural racism is a reasonable explanation. Those that put it forward need to provide evidence."

\section{Recommendations}

The report makes 13 recommendations for action across government, all of which have been accepted by the prime minister. These include ensuring that NHS trusts implement plans for the next stage of the pandemic that reflect the latest evidence about ethnic disparities and risk factors, as well as updating the list of "shielded" patients in line with improved knowledge of the factors that put people at greatest clinical risk.

Recording ethnicity as part of the death certification process should become mandatory, "as this is the only way of establishing a complete picture of the impact of the virus on ethnic minorities," the report says.

It also calls for government departments to monitor the effects of their policies on people from ethnic minority backgrounds, to continue to work at pace to develop new policy interventions to mitigate covid-19 disparities, and to improve public health communication to enable interventions to be delivered successfully to everyone.

\section{Build confidence}

The report notes that "further work is needed to partner with health professionals to dispel myths, reduce fear and build confidence among ethnic minority people.” The government “will need to keep sharpening its focus on rebuilding trust in government messaging, tackling misinformation and anti-vaccination narratives and encouraging engagement with NHS services," it advises.

Trish Greenhalgh, professor of primary health care services, University of Oxford, said, "It is encouraging that a government report is considering what might be called the structural causes of inequalities as well as the [possibility of] biological ones. In other words, a person from a black or south Asian background may be more likely to develop covid-19, and more likely to become seriously ill and die from it, not just for biological reasons-eg, more likely to have comorbidities such as diabetes-but also, and perhaps primarily, for reasons linked to poverty and social injustice.”

However, Chaand Nagpaul, BMA council chair, complained about the delay in the government's response. People from ethnic minority backgrounds had not seen any change in the disproportionate effects of the virus on their lives, he said.

"Today, as we sit amid a second wave of infections, we know that about a third of those admitted to intensive care are not white-showing no change since the first peak. Meanwhile, black and Asian 
people have been found twice as likely to be infected compared to white people," Nagpaul explained.

He added, "There needs to be more tangible action right now to protect BAME [black, Asian, and minority ethnic] people. This could include providing resources to support individuals and businesses to ensure they have right protective equipment and to ensure their workplaces are covid secure. With higher numbers of BAME people in low paid employment or living in deprived areas, it is vital to offer adequate funding that encourages individuals to be tested and to self-isolate if infected, given evidence that many feel that financial loss acts as a deterrent to do so.

"The Community Champions scheme is welcome, but we need to see the reality of culturally competent public health and disease prevention strategies with ownership and trust in communities now, so that there are necessary behaviour changes to prevent more from coming to harm."

1 Government HM. Race Disparity Unit. Quarterly report on progress to address covid-19 health inequalities. 22 Oct 2020. https://www.gov.uk/government/organisations/race-disparity-unit.

2 lacobucci G. Covid-19: Racism may be linked to ethnic minorities' raised death risk, says PHE. BMJ 2020;369:m2421. doi: 10.1136/bmi.m2421 pmid: 32554546

This article is made freely available for use in accordance with BMJ's website terms and conditions for the duration of the covid-19 pandemic or until otherwise determined by BMJ. You may use, download and print the article for any lawful, non-commercial purpose (including text and data mining) provided that all copyright notices and trade marks are retained. 